Sedeillán, G. El código procesal penal bonaerense de 1915: primeras iniciativas de reforma en la Legislatura a tres años de vigencia. Derecho y Ciencias Sociales. Abril 2018. N 18. Pgs 234-251. ISNN 1852-2971. Instituto de Cultura Jurídica y Maestría en Sociología Jurídica. FCJ y S. UNLP

\title{
El código procesal penal bonaerense de 1915: primeras iniciativas de reforma en la legislatura a tres años de vigencia
}

The Buenos Aires criminal procedure code of 1915: criticisms and initiatives of reform in the legislature to three years of validity

\section{Gisela Sedeillan}

\section{Resumen}

El presente artículo posa la mirada en los primeros proyectos de reforma del código procesal penal de 1915 presentados en la legislatura bonaerense. Analiza sus contenidos y si existió consenso para que sean sancionados con el objetivo principal de identificar las preocupaciones que impulsaron cambios en el texto legal. Se centra en la primera gobernación de la Unión Cívica Radical (1918-1921), escenario político caracterizado por tensiones entre el gobernador Crotto y la Legislatura.

Palabras clave: Código procesal de 1915; proyectos legislativos de reforma; Provincia de Buenos Aires.

\begin{abstract}
The present article looks at the first projects of reform of the criminal procedural code of 1915 presented in the legislature of the province of Buenos Aires. Analyze its contents and if there was consensus so that they are sanctioned with the main objective of identifying the concerns that prompted changes in the legal text. It focuses on the first government of the Unión Cívica Radical (1918-1921), a political scenario characterized by tensions between Governor Crotto and the Legislature.
\end{abstract}

Keywords: Procedural code of 1915; Legislative reform projects; Province of Buenos Aires

\footnotetext{
- Doctora en Historia, Investigadora del IGEHCS-IEHS-CONICET en la UNICEN. Miembro titular del INHIDE. Correo electrónico: giselatandil@ hotmail.com .
}

Recibido: 19/9/2017 Aceptado con correcciones: 15/03/2018 
Sedeillán, G. El código procesal penal bonaerense de 1915: primeras iniciativas de reforma en la Legislatura a tres años de vigencia. Derecho y Ciencias Sociales. Abril 2018. № 18. Pgs 234-251. ISNN 1852-2971. Instituto de Cultura Jurídica y Maestría en Sociología Jurídica. FCJ y S. UNLP

\section{El código procesal penal bonaerense de 1915: primeras iniciativas de reforma en la legislatura a tres años de vigencia ${ }^{1}$.}

Gisela Sedeillan

\section{Introducción}

A comienzos de 1915 se ponía en vigencia en la provincia de Buenos Aires un nuevo código procesal penal, cuyo texto que había nacido de preocupaciones por fortalecer las garantías del imputado, acelerar los procedimientos y descomprimir la congestión de las cárceles en un contexto de influencia del discurso criminológico positivista. ${ }^{2}$ El mismo era fruto de un trabajo meditado, sus antecedentes datan de 1907, cuando Tomás Jofré se incorporó a la legislatura como diputado y dio impulso a la reforma procesal penal. ${ }^{3} \mathrm{Su}$ proyecto pasó por varias comisiones y modificaciones porque si bien imperaba un clima político crítico en relación al sistema penal, existieron disidencias entre los legisladores acerca de hasta donde debía darse alcance al fortalecimiento de las garantías procesales. (Sedeillan, 2013.) ${ }^{4}$

En el ámbito legislativo no existieron cuestionamientos al código de 1915 hasta que José Cantilo, interventor nacional de la provincia en 1917, se pronunció en su contra. Señaló que alentaba la impunidad y la necesidad de incorporar en la agenda política su modificación. ${ }^{5}$ Apreciación que fue compartida por el gobernador electo en 1918 por la Unión Cívica Radical, Camilo Crotto, quien a pocos meses de haber asumido la gobernación, propuso en la legislatura el restablecimiento del código procesal sancionado en 1906 hasta tanto se

\footnotetext{
${ }^{1}$ El trabajo forma parte de una investigación más amplia que se detiene en el análisis de la administración de justicia penal entre 1916 y 1930 a fin de ver los cambios y continuidades que se dieron con el triunfo del radicalismo en el espacio bonaerense.

2 El positivismo criminológico impulsaba la condena condicional; el rechazo parcial de la pena privativa de libertad; la separación del derecho penal para los jóvenes del relativo a los adultos, etc. Véase, entre otros Zimmermann (1995) Marteau, (2003); Caimari, (2004); Salvatore (2010). Aunque el positivismo criminológico surgido en Europa tuvo profunda repercusión en la Argentina, el proceso histórico de adaptación teórica tuvo matices, contradicciones y tensiones. Al respecto: Cesano (2011).

${ }^{3}$ En 1908, Jofré presentó un proyecto que fue aprobado con modificaciones por la Cámara de Diputados, pero el Senado no lo trató. Nuevamente lo impulsó con reformas en Diputados en 1912, la legislatura lo sancionó con cambios el 15-1-1915. Ley 3.589.

${ }^{4}$ Aunque Jofré señalaba que era un "enorme paso adelante con respecto al anterior", lo consideraba "solo una conquista mínima de lo que el progreso del país exige: jurados, instancia única, juicio oral en toda su plenitud y pruebas morales: Nuevo código de procedimiento penal de la provincia de Buenos Aires con prólogo de Tomás Jofré. (1915). Buenos Aires: Valerio Abeledo, p. 28.

${ }^{5}$ La intervención puso fin a más de treinta años en los que el conservadurismo había dominado la escena política. Acerca de las prácticas políticas que introdujo la democratización: Devoto y Ferrari; (1994); Melon y Pastoriza, (1996), Ferrari (1994), (Persello, 2007) entre otros.
} 
Sedeillán, G. El código procesal penal bonaerense de 1915: primeras iniciativas de reforma en la Legislatura a tres años de vigencia. Derecho y Ciencias Sociales. Abril 2018. № 18. Pgs 234-251. ISNN 1852-2971. Instituto de Cultura Jurídica y Maestría en Sociología Jurídica. FCJ y S. UNLP

estudiasen reformas a dicho corpus. Su iniciativa apuntaba en particular a atender la represión del cuatrerismo, una agenda pendiente que generaba demandas por parte de los hacendados.

Este trabajo detiene la mirada en las sesiones de la Cámara de Diputados y Senadores bonaerense a fin de identificar los primeros diagnósticos críticos efectuados a la legislación procesal penal de 1915 en el ámbito político. Los objetivos se centran en analizar las preocupaciones que impulsaron tempranamente proyectos de reformas al texto legal, en qué medida gozaron de consenso y si anuncian cambios en la política criminal. Atendiendo la renovación del elenco político dada con la democratización, focalizaremos la atención en la primera gobernación radical de Camilo Crotto. ${ }^{6}$ En suma, el trabajo pretende contribuir a un análisis que dé cuenta de las tensiones y los vaivenes que existieron por parte de los gobernantes a lo largo de la historia argentina al intentar proyectar el diseño de una justicia acorde al estado de derecho liberal.

\section{Lecturas críticas del código procesal penal de 1915}

El código procesal no dejó atrás las instituciones del modelo inquisitivo, aunque introdujo algunas innovaciones a fin de reforzar las garantías procesales. ${ }^{7}$ Incorporó a elección del imputado el procedimiento oral e instancia única en delitos graves, liberalizó la instrucción permitiendo una actividad mayor del acusado y su defensor durante su transcurso y limitó el encarcelamiento preventivo en delitos con pena privativa de la libertad superior a dos años de prisión en su término medio. (Maier, 1989: 191) Efectivamente, en los delitos correccionales se eliminó la incomunicación durante el sumario y en aquellos castigados con presidio, penitenciaria o muerte se fijó en cinco días mientras que el secreto del sumario regía para el fiscal como para el defensor. ${ }^{8}$ (Jofré, 1915: 188)

\footnotetext{
${ }^{6}$ Crotto asumió en mayo de 1918 y renunció en 1921 presionado por la amenaza de intervención nacional, la falta de apoyo de la legislatura y del partido por disputas con el presidente. Asumió el vice-gobernador Monteverde hasta completar el período de gobierno (1922). Véase: Barba, (2010). Los documentos utilizados son los Diarios de Sesiones de la legislatura provincial y el Registro Oficial. Complementamos la información con la lectura del Diario El Día de la ciudad de La Plata y El Ciudadano de Azul.

${ }^{7}$ El juez que dirige la investigación sigue siendo quien sentencia, está alejado del modelo acusatorio en el que el juez actúa como un árbitro, la prueba es producida en el debate y su valoración atiende a la libre convicción. Sobre este modelo, un clásico: Vélez Mariconde (1969); Maier (1989). La matriz histórica de la justicia penal inquisitorial ha perdurado, entre otras razones por su funcionalidad política: Binder, (2016: 62.)

${ }^{8}$ Con respecto al sistema de enjuiciamiento penal federal bajo el Código de Procedimientos en lo Criminal y Correccional de 1889, de neto corte inquisitivo: Guariglia y Bertoni, (2000: 51- 6); Salvatore (2010)
} 
Sedeillán, G. El código procesal penal bonaerense de 1915: primeras iniciativas de reforma en la Legislatura a tres años de vigencia. Derecho y Ciencias Sociales. Abril 2018. N 18. Pgs 234-251. ISNN 1852-2971. Instituto de Cultura Jurídica y Maestría en Sociología Jurídica. FCJ y S. UNLP

Antes de la sanción de este corpus, algunos legisladores manifestaron dudas acerca de incorporar los cambios detallados y ello explica las distintas comisiones que lo estudiaron y las modificaciones que experimentó. ${ }^{9}$ Aun en un contexto de preocupación por la sobrepoblación en las cárceles, la gran cantidad de procesados a la espera de una condena y la falta de regeneración del delincuente en esos espacios (Caimari, 2004), en la legislatura bonaerense se interpusieron reparos en ampliar la libertad provisoria durante el proceso en causas correccionales (Sedeillan, 2013).

El código fijó que los menores de 15 que no fueran reincidentes no podían ser detenidos preventivamente durante el juicio independientemente del delito en cuestión. En delitos correccionales, cuya pena no era superior a dos años de prisión en su término medio, estableció que no procedía la prisión preventiva a excepción de ser reincidente, no tener domicilio en la provincia, ser prófugo o si existiesen motivos para creer que burlaría la acción de la justicia. Facilitó acceder a la libertad procesal simplificando el trámite, pues se sustanciaba sin necesidad de pedido del defensor. El artículo 173, determinó que podría detenerse por el término de 8 días, a objeto de recibirle al acusado la indagatoria, de que fije domicilio legal y de instruir las primeras diligencias sumariales. No obstante, los atentados a la propiedad parecían entrañar una gravedad social mayor, en tanto en delitos de robos o hurtos con pena correccional, se restringió este beneficio bajo requisito de fianza. (Jofré, 1915: 313.) Esta limitación no formaba parte del proyecto aprobado en Diputados, (Jofré: 1914) fue introducida por el Senado y señalada como injusta por especialistas de derecho. ${ }^{10}$

Algunos legisladores interpusieron reparos al momento de sancionar el código señalando que alentaría la impunidad. Es difícil precisar si ello efectivamente ocurrió debido a la carencia de datos estadísticos fiables, ${ }^{11}$ ya antes de la sanción de dicho corpus la información oficial señalaba el aumento progresivo de la criminalidad. Para 1915 el gobernador por el partido conservador, Marcelino Ugarte, informaba 15.885 delitos acaecidos contra 12.325 en 1914 , de los cuales 10.203 eran contra la propiedad y 5.679 contra las

\footnotetext{
${ }^{9}$ Aunque los conservadores dominaron la escena política hasta 1917, existían disidencias entre ellos en distintos aspectos, por ejemplo sobre la administración y el sistema electoral: véase: Tatto, (2005); Fernandez Irusta (2006).

${ }^{10}$ Como el fiscal de la Cámara de Apelaciones del departamento Costa Sud, véase: Palomeque (1916) y Rojas, abogado encomendado por Jofré para comentar el código procesal: Jofré, (1915, p. XXX)

${ }^{11}$ Datos oficiales que deben leerse con cuidado al evaluar el crecimiento de la criminalidad. Como sostiene Caimari, en estas décadas las denuncias por delitos aumentaron a un ritmo más acelerado que los arrestos y la tasa de detenidos por crimen cometido descendió. (Caimari: 2004: 81)
} 
Sedeillán, G. El código procesal penal bonaerense de 1915: primeras iniciativas de reforma en la Legislatura a tres años de vigencia. Derecho y Ciencias Sociales. Abril 2018. № 18. Pgs 234-251. ISNN 1852-2971. Instituto de Cultura Jurídica y Maestría en Sociología Jurídica. FCJ y S. UNLP

personas. ${ }^{12}$ Quien le sucedería en 1917, José Cantilo, también mencionaba el incremento del crimen durante el tiempo que se desempeñó como interventor de la provincia. Enumeraba unos 15.794 delitos contra la propiedad entre 25-4-1917 y 31-3-1918, al tiempo que informaba que de los 18.419 autores probables solo 12.679 habían sido apresados. Menor número de no capturados registraban los delitos contra la vida, en tanto no lo fueron 1.366 de un total de 6. 861 presuntos culpables. (Cantilo, 1918: 61-63)

Los datos oficiales ilustran la importancia que revestían los delitos contra la propiedad y dan cuenta de la dificultad para detener a los presuntos culpables. Entre los factores del incremento de la criminalidad Ugarte había señalado la crisis económica y los pocos efectivos policiales. ${ }^{13}$ Cantilo sumó como causas la escasa capacidad de las normas para afianzar la propiedad privada. En su informe acerca de su labor como interventor, indicó la necesidad de modificar el código procesal por ser "pródigo en clausulas" y facilitar la "impunidad de la delincuencia”.(Cantilo,1918: 61-63). ${ }^{14}$ Apreciación compartida por Crotto, quien a pesar de señalar en su mensaje a la legislatura de 1919 que las infracciones penales se habían reducido de 21.455 en 1917 a 18.019 en 1918, destacó como obstáculos para atacar el cuatrerismo "la deficiencia de las leyes, especialmente la de fianza carcelaria, el código procesal vigente". 15

\section{Propuestas para reprimir la criminalidad}

\subsection{Aumento de policía}

El discurso de Crotto en la legislatura a un año de iniciar su mandato refleja que el problema de la seguridad excedía a la institución policial, aunque lejos estaba de excluirla. Pese a que el número de vigilantes fijado en el presupuesto de gastos para 1918 era de 4.113, superior al de 1917 que alcanzaba los 3.883, lo señaló insuficiente ante el crecimiento poblacional y las variadas tareas que desempeñaban. También destacó como un obstáculo las bajas remuneraciones para lograr la estabilidad del plantel. ${ }^{16}$ A pesar de la inflación y la

\footnotetext{
${ }^{12}$ Sesión 8-5-1916, Diario de sesiones Cámara de Diputados de la provincia de Buenos Aires, La Plata, 1917, p.67. En adelante (DSCD).

${ }^{13}$ DSCD (1917), sesión 8-5-1916, p. 55.

${ }^{14}$ Los diarios analizados acusan el incremento de robos y lo relacionan en particular a la falta de personal policial. El crimen tomará protagonismo en la prensa nacional en los años siguientes, véase: Caimari (2009)

${ }^{15}$ Sesión 5-5-1919, Diario de sesiones de la Cámara de Senadores, 1919, p. 9. En adelante (DSCS). El número que brinda para 1917 es superior a aquel que informa Cantilo.

${ }^{16}$ DSCS (1918), sesión, 27-8-1918.
} 
Sedeillán, G. El código procesal penal bonaerense de 1915: primeras iniciativas de reforma en la Legislatura a tres años de vigencia. Derecho y Ciencias Sociales. Abril 2018. № 18. Pgs 234-251. ISNN 1852-2971. Instituto de Cultura Jurídica y Maestría en Sociología Jurídica. FCJ y S. UNLP

elevación del costo de vida como consecuencia de la guerra, (Gerchunof, 2016: 67-71) el sueldo asignado al personal en el presupuesto de 1918 era menor que en el de $1914 .^{17}$

El propósito de reforzar presupuestariamente la partida policial perseguía atender no solo el problema del cuatrerismo sino también la ola de huelgas. El gobernador refería a 129 acontecimientos de este tipo acaecidos en $1918,{ }^{18}$ caracterizados por largos paros de obreros ferroviarios y también de gremios diversos en las principales ciudades fabriles (Ascolani, 2013: 406). La gran novedad fue la sindicalización masiva de los trabajadores rurales de baja calificación, vinculados a la tarea de estiba y cosecha. El conflicto se extendió hasta 1921 en la mayoría de los oficios a causa de la internalización de la agitación proletaria y las expectativas de recomposición salarial de la posguerra. (Ascolani, 2013: 406)

Las primeras iniciativas en la legislatura para elevar los sueldos provinieron de algunos diputados del radicalismo, quienes a mediados de 1918 presentaron un proyecto en tal sentido. Por su parte, Crotto envió a la legislatura en septiembre de 1918 el proyecto de presupuesto de gastos para el año siguiente solicitando el aumento del personal y de las remuneraciones. ${ }^{19}$ Insistió el 2 de noviembre de 1918 en el incremento salarial a fin de "llevar a cabo en forma eficiente la campaña emprendida contra el abigeato." ${ }^{20}$ Preocupación que reiteró dos meses después, ante la sanción en el Senado del presupuesto de 1918 para enero y febrero de 1919 sin modificaciones al respecto. ${ }^{21}$ Recién a fines de marzo de 1919 se aprobó dicho incremento retroactivo a enero, ${ }^{22}$ aunque se admitía que era insuficiente. El aumento de efectivos debió esperar a julio, al sancionarse el presupuesto para lo que restaba del año. El número fue menor del propuesto por el gobernador, los vigilantes se elevaron de 4.113 a 4.500 y los gendarmes volantes de 180 a $600 .^{23}$

Contribuyeron a postergar el aumento de las partidas presupuestarias destinadas a la policía consideraciones de tipo económico, ${ }^{24}$ cuestionamientos a la participación represiva de

17 Véase presupuesto 1818. Recuperado el 20 de septiembre de 2017 de http://www.gob.gba.gov.ar/intranet/digesto/PDF/03655.pdf.

${ }^{18}$ DSCS (1919), sesión 5-5-1919, p. 9.

${ }^{19}$ DSCS (1918), sesión 10-9-1918 p. 811.

${ }^{20}$ DSCD (1919) sesión 6 -11- 1918, p. 1640.

${ }^{21}$ DSCD, (1919) sesión 22-1-1919.

${ }^{22}$ El sueldo de los vigilantes se elevó de 70 a 90 pesos. Véase ley número 3.677. Se incorporó al presupuesto para marzo y abril de 1919: (DSCD) 1919, p.1927. Años en que se retornó la práctica de poner en vigencia presupuestos de años anteriores, haciendo uso de duodécimos. Véase: Degregori, D. (1996).

${ }^{23}$ Los legisladores señalaron que el gobernador pedía el aumento de 1.500 efectivos. El presupuesto fue sancionado el 27-6-1919 y el ejecutivo vetó algunos de sus artículos. Ley 3.681.

${ }^{24}$ No fue hasta los gobiernos de Cantilo y Vergara cuando la economía bonaerense comenzó a recuperarse lo que propició un rápido aumento del presupuesto: Regalsky y Da Orden (2013). 
Sedeillán, G. El código procesal penal bonaerense de 1915: primeras iniciativas de reforma en la Legislatura a tres años de vigencia. Derecho y Ciencias Sociales. Abril 2018. N 18. Pgs 234-251. ISNN 1852-2971. Instituto de Cultura Jurídica y Maestría en Sociología Jurídica. FCJ y S. UNLP

la policía en las huelgas, ${ }^{25}$ así como también las tensiones políticas que existían con el gobernador. Como han señalado distintos trabajos, aunque el radicalismo tenía mayoría en ambas cámaras se dividió a poco de asumir Crotto debido al conflicto que lo enfrentó con el presidente Yrigoyen. ${ }^{26}$ Conformó gabinete sin consultarlo y desconoció cargos hechos por el interventor a pedido del presidente, produciéndose tensiones entre el gobernador y los órganos partidarios. Enfrentamiento que se superponía a los conflictos que existían dentro del partido ya antes de asumir Crotto, entre los provincialistas, quienes defendían la autonomía provincial y los metropolitanos que tenían vínculos con el radicalismo nacional y la capital federal. ${ }^{27}$ El conflicto se trasladó a la legislatura traduciéndose en la oposición a las iniciativas de Crotto, ya sea mediante la inactividad legislativa, la indiferencia hacia sus proyectos o las interpelaciones a ministros. (Ruffini, 1993: 38); (Barba: 2007).

Esas tensiones políticas, sin embargo, no son suficientes para explicar por qué no prosperaron otras iniciativas del gobernador para reprimir la criminalidad, como fue su propuesta de derogar el código de procedimientos en materia penal cuando asumió el cargo.

\subsection{Proyectos de reformas del código procesal penal}

El 31 de octubre de 1918, Crotto enviaba un proyecto a la legislatura que derogaba el código procesal para que fuera tratado en sesiones extraordinarias junto a otros siete asuntos que consideraba de "interés público y de urgencia". ${ }^{28}$ Lo fundamentaba en los obstáculos que imponía para reprimir el cuatrerismo, sin apoyarse en datos cuantitativos o en detallar aquellos aspectos que validaban su modificación. Atendiendo que Crotto además de abogado era un importante propietario de tierras dedicadas especialmente a la ganadería, ${ }^{29}$ nos preguntamos en qué medida su lectura era compartida por aquellos legisladores que no lo eran.

El pedido de Crotto fue rechazado en Diputados. El legislador Salcedo señaló desde la oposición que su propuesta no era de carácter urgente como para tratarla en sesiones

\footnotetext{
${ }^{25}$ Acercas de las denuncias a la policía Ruffini (1993: 41)

${ }^{26}$ Persello señala que en la mayoría de las provincias el radicalismo se dividió una vez que ocupó el gobierno. (2000: 68-69); (2013: 297-298).

${ }^{27}$ Destacados trabajos señalan estas tensiones políticas: Walker (1987); Ruffini, (1993); Barba, ( 2007; 2009; 2010), Persello, (1996, 2013)

${ }^{28}$ DSCD, (1919) sesión 6-11-1918, p. 1639.

${ }^{29}$ Poseía aproximadamente 15.000 hectáreas, principalmente en la provincia. Formó parte de la Sociedad Rural e integró su comisión directiva.: (Ruffini: 1993: 35-37); Acerca de su mandato: Barba (2010)
} 
Sedeillán, G. El código procesal penal bonaerense de 1915: primeras iniciativas de reforma en la Legislatura a tres años de vigencia. Derecho y Ciencias Sociales. Abril 2018. N ${ }^{\circ}$ 18. Pgs 234-251. ISNN 1852-2971. Instituto de Cultura Jurídica y Maestría en Sociología Jurídica. FCJ y S. UNLP

extraordinarias, pronunciándose en el mismo sentido su compañero de banca Ruiz Guinazú. ${ }^{30}$ Si bien este último, en 1914, había puesto reparos a la sanción del código argumentando que alentaría la impunidad, en esta oportunidad sostenía que la propuesta del gobernador requería un "debate amplio y un estudio detenido. ${ }^{31}$ La comisión del Senado recién se dispuso a debatirla el 24-6-1919. Sus integrantes, el conservador Olaso y los radicales Pavón y Nuñez, invitaron al ministro de gobierno a participar del debate a desarrollarse en la próxima sesión, sin embargo, el proyecto no fue discutido. Aunque Olaso adelantó que la comisión se pronunciaría por su rechazo, el gobernador hizo saber a la cámara su decisión de retirar el proyecto de cartera bajo el argumento de estar preparando uno nuevo que introducía modificaciones al corpus vigente. ${ }^{32}$

La decisión del ejecutivo provincial parecía responder a la falta de voluntad política que anunciaba la legislatura para tratar su pedido. El senador Agustín Gambier, destacado legislador por el partido conservador, se opuso a la propuesta de sacar de vigencia un código cuya sanción reposaba en el eje crítico de la vulnerabilidad del proceso penal en relación al delincuente. La calificó de "sorprendente y barata (...) por el escaso esfuerzo que requirió en los promotores del pensamiento". 33 Sostenía que existían deficiencias pero "estaban compensadas por un cúmulo de garantías que afianzaban la libertad individual, siendo preferible cien delincuentes en libertad a un inocente en la cárcel!.” ${ }^{34}$ Conservadores y radicales que se pronunciaron al respecto señalaban el salto cualitativo que representaba el código. Los discursos presentaban la propuesta de Crotto como un paso atrás, no obstante, coincidían en que no eran todas luces aquellas que irradiaban de su letra.

Legisladores que habían sido referentes del impulso de la reforma procesal hacia 1915, como Agustín Gambier y Tomás Jofré, subrayaron que la poca eficacia en la persecución penal no dependía únicamente del código procesal. No obstante, lejos de centrarse en destacar las deficiencias superadas por éste, consideraron necesario modificar algunos de sus artículos y presentaron proyectos en tal sentido. Así también lo hizo el senador radical recién arribado a la cámara, José T. Olmos ${ }^{35}$ y el diputado por el mismo partido

\footnotetext{
${ }^{30}$ DSCD, (1919) sesión 6-11-1918, p.1646

${ }^{31}$ DSCD, (1919) sesión 6-11-1918, p.1646

${ }^{32}$ DSCS, (1919) sesión 1-7-1919.

${ }^{33}$ DSCS, (1919) sesión 1-7-1919, p. 157.

${ }^{34}$ DSCS, (1919) sesión 1-7-1919, p. 157.

${ }^{35}$ La normalización del proceso electoral en la provincia llevó a radicales a iniciarse en cargos de gobierno: en el caso de José T. Olmos (1918) como senador. Al respecto, Ferrari, (2008).
} 
Sedeillán, G. El código procesal penal bonaerense de 1915: primeras iniciativas de reforma en la Legislatura a tres años de vigencia. Derecho y Ciencias Sociales. Abril 2018. N 18. Pgs 234-251. ISNN 1852-2971. Instituto de Cultura Jurídica y Maestría en Sociología Jurídica. FCJ y S. UNLP

Guillermo González. En particular, todos compartían una preocupación en común: las dificultades para penalizar el hurto de animales y la común reincidencia por este delito.

La mayoría de las iniciativas de reforma señalaban algunos artículos del código de 1915 por restar eficacia en la investigación criminal. Por ejemplo, la prohibición en delitos correccionales del secreto de la investigación durante el sumario, también el plazo no mayor de cinco días de incomunicación fijado para aquellos castigados con presidio, penitenciaria o muerte. Asimismo, se cuestionó que la confesión prestada solo ante el juez tuviera validez, proponiéndose, como lo hizo en 1918 el diputado radical Guillermo González, que también lo fuera ante el comisario instructor. Argumentaba que los autores de robos o hurtos:

"burlan la acción de la justicia negando las declaraciones hechas ante la policía, pretextando en muchas ocasiones haber declarado presionados por el comisario, esto en los casos en que no utilizan el procedimiento de negar rotundamente todo cuanto aparece en el sumario incoado y firmado por los presuntos autores (...) vemos a cada instante el espectáculo nada edificante de que autores de delitos confesados ante la policía, son remitidos por esta a la cárceles y apenas declaran ante el juez son puestos en libertad por falta de plena prueba". 36

En consonancia con la preocupación de González, meses más tarde, precisamente el 17-1919, Gambier presentaba un proyecto en el Senado que incorporaba el juicio oral como obligatorio en causas de hurto mayor o menor de ganado a fin de otorgar al proceso mayor celeridad y transparencia El objetivo era atacar la principal razón que a su entender impulsaba el cuatrerismo: la impunidad. Destacaba que:

"Todos los días se nos presenta un caso en que la justicia se ha visto obligada a dejar en libertad a cuatreros convictos ante la policía del delito imputado, y esa impunidad no solo desalienta a los funcionarios encargados de velar por el respeto de la propiedad, sino que produce el pánico entre los productores que se sienten indefensos ante el avance creciente de la delincuencia. El vulgo culpa de esta impunidad a "la mala justicia" términos comprensivos de policía y jueces. Los más avisados, y entre nosotros no pocos funcionarios, la hacen responsable a la nueva ley de enjuiciamiento en materia penal.",37

\footnotetext{
${ }^{36}$ DSCD, (1919) sesión 4-10-1918, p. 1397.

${ }^{37}$ DSCS, (1919). sesión 1-7-1919, pp. 155 - 156.
} 
Sedeillán, G. El código procesal penal bonaerense de 1915: primeras iniciativas de reforma en la Legislatura a tres años de vigencia. Derecho y Ciencias Sociales. Abril 2018. N 18. Pgs 234-251. ISNN 1852-2971. Instituto de Cultura Jurídica y Maestría en Sociología Jurídica. FCJ y S. UNLP

Gambier coincidía con González en identificar como un problema la validez legal de la confesión prestada solo ante el juez. Sostenía que restaba a las actuaciones policiales la eficacia que le atribuía el código anterior". ${ }^{38}$ Además, planteó un conjunto de problemas de eficacia en la persecución penal que excedían cuestiones relacionadas con la legislación de fondo y de forma. Cuestionó a la policía en un contexto de convicción generalizada sobre defectos en su organización. En particular señaló la calidad de los agentes encargados de la instrucción del sumario, aún mal remunerados, por distorsionar el funcionamiento de las reglas procesales. ${ }^{39}$ Sostuvo que el procedimiento escrito era deficiente porque estaba "en manos de funcionarios incompetentes que recogen pruebas en forma incompleta y muchas veces ilegal (...) el procesado -por lo general un profesional experimentado en la especialidad del abigeo- está autorizado a destruir ante el juez todo el material reunido por la policía". ${ }^{4}$ Precisamente, la falta de preparación de los agentes en la instrucción sumarial no era una novedad, también por entonces fue señalada en el ámbito jurídico por revestir vicios de nulidad e inutilizar en algunos casos la única prueba de cargo. ${ }^{41}$

En los discursos se hacía explícita la preocupación por la impunidad delictiva. Gambier destacó la dificultad para penalizar como autor al presunto culpable siendo frecuente las condenas por encubrimiento y las bajas penas que fijaba el código penal por esta figura. ${ }^{42}$ Apreciaciones que coincidían con aquellas emitidas por el Juez del crimen del departamento del Centro, quien señalaba que si la escala de la pena por hurto de ganado era de dos hasta seis años de penitenciaría y por cómplice de tres a seis años, por encubrimiento correspondía un máximo de un año de arresto de no superar la pena general los seis años. Sostenía que la justicia se decidía de manera amplia por el encubrimiento por tratarse de "de situaciones en que solo se ponen de manifiesto actos posteriores del delito, ante las excusas invocadas por los prevenidos". (Villar, 1921: 60) Este juez remarcó el bajo número de sumarios instruidos que llegaban a sentencia; informaba que en su juzgado entre el 1-12-1918 y el 29-2-1920

\footnotetext{
${ }^{38}$ DSCS, (1919), sesión, 1-7-1919, p.157

${ }^{39}$ Como sostiene Barreneche y Galeano, los reclamos sobre la escasez de personal y el bajo nivel de salarios fue una constante discursiva entre los reformadores durante el período tratado: (2008: 87).

${ }^{40}$ DSCS (1919). sesión 1-7-1919, p. 157.

${ }^{41}$ Aun así, las pesquisas criminales y el uso de medios técnicos y científicos para dicho fin continuaron en manos de la policía de investigaciones: Barreneche (2010)

${ }^{42}$ Por entonces estaba pendiente de sanción en el Senado nacional el proyecto de código penal que impulsaba Rodolfo Moreno a fin de reducir el número de penas, individualizarlas y otorgar a los jueces mayores facultades para que puedan aplicarlas dentro de términos más amplios según el caso. Fue sancionado en septiembre de 1921. Aspectos detallados en Moreno, R. (1922)
} 
Sedeillán, G. El código procesal penal bonaerense de 1915: primeras iniciativas de reforma en la Legislatura a tres años de vigencia. Derecho y Ciencias Sociales. Abril 2018. N 18. Pgs 234-251. ISNN 1852-2971. Instituto de Cultura Jurídica y Maestría en Sociología Jurídica. FCJ y S. UNLP

existieron 500 causas entradas por abigeato, 427 terminaron sin condena y de las 72 causas falladas solo 58 fueron sentencias condenatorias. (Villar, 1921: 100)

Mientras ese proyecto esperaba despacho de la comisión, el senador radical José T. Olmos, también presentaba una propuesta de modificación del código procesal movido por las mismas preocupaciones. Señaló que el corpus "tenía fallas de significación (...) una marcada liberalidad en ciertos casos que contrasta con el rigorismo de otros, lo que es conveniente atemperar pues resulta inadaptable a nuestro ambiente, dadas las modalidades y costumbre de nuestro pueblo". 43

La ampliación de la publicidad del sumario fue un aspecto que Olmos cuestionó. Destacó que traía aparejados inconvenientes para la administración de justicia que se agravaban por la carencia de valor que muchas veces se les atribuía a las declaraciones indagatorias recibidas por la policía. Al respecto argumentó que: "La enorme extensión del territorio, las dificultades que en gran parte se observan en las comunicaciones, la exigüidad de los medios de movilidad, y otros recursos con los que se tropieza, concurren a hacer más dificultosa la investigación a base de amplia publicidad." 44 Aunque no proponía ampliar el término de la incomunicación, sí establecer que en toda causa el sumario sería secreto mientras el juez no haya tomado la declaración indagatoria, tal como fijaba el código anterior.

Como puede observarse, a fin de evitar la impunidad, los proyectos otorgaban significativo peso al sumario como centro de la escena procesal. En relación a ello Olmos cuestionó algunos derechos otorgados a la defensa vinculados con el contralor de las pruebas. El artículo 242 autorizaba a pedido de parte la ratificación de los testigos del sumario en el plenario, posibilitando la información de abono: si estos estuvieren ausentes o muertos, dos o más personas de probidad podían exponer sobre el concepto de veracidad que les merecían. Olmos modificaba el artículo 243 eliminando la disposición que establecía que cuando no se hubiere practicado dicha información las declaraciones no podrían oponérsele a la parte si ésta las hubiere observado. Fundamentó su modificación en la frecuencia de que depusieran como testigos "transeúntes, trabajadores de campo, jornaleros, etc. que llevan una vida casi nómade y cuyo comparendo en el plenario resulta poco menos que imposible". ${ }^{45}$ Las reformas también apuntaban a darle mayores atribuciones al juez, por lo que modificaba el artículo 433 que

\footnotetext{
${ }^{43}$ DSCS (1919). sesión 15-7-1919, p. 180.

${ }^{44}$ DSCS (1919). sesión 15-7-1919, p. 181

${ }^{45}$ DSCS (1919). sesión 15-5-1919, p. 183. Los expedientes que actualmente nos encontramos analizando, pertenecientes al Departamento judicial Sud, reflejan que constituía un motivo legítimo de preocupación.
} 
Sedeillán, G. El código procesal penal bonaerense de 1915: primeras iniciativas de reforma en la Legislatura a tres años de vigencia. Derecho y Ciencias Sociales. Abril 2018. N 18. Pgs 234-251. ISNN 1852-2971. Instituto de Cultura Jurídica y Maestría en Sociología Jurídica. FCJ y S. UNLP

prohibía al juez fallar en un proceso correccional con pena mayor que la pedida por el fiscal y aceptada por la defensa .

Los tiempos acotados otorgados al fiscal y al defensor para expedirse en causas correccionales fueron otros de los puntos bajo la lupa. Olmos propuso concederles la posibilidad de solicitar prórroga en causas correccionales tal como lo habilitaba el código en causas graves. Su proyecto también ampliaba el plazo otorgado al juez para dictar o no la prisión preventiva, fijándolo hasta 15 días después de tomarle declaración al imputado, en tanto el código estipulaba tres días sí el acusado lo solicitaré, no pudiendo superar los 10 a partir de la fecha de la indagatoria (art. 181). Argumentó la importancia de esta reforma porque:

"sabido es que los sumarios policiales adolecen, en su mayoría, de serias deficiencias que el juez debe subsanar ordenando ampliaciones (...) Son igualmente notorias las dificultades de comunicación en la provincia y la exigüidad de los medios con los que cuentan los instructores para llevar a cabo el comparendo de testigos y la práctica de las demás diligencias sumariales. ¿cómo es posible entonces exigir que el juez dicte su auto en el angustioso término de tres días, por la sola razón de que así lo pida el reo? ¿cuál puede ser el motivo de este privilegio?". ${ }^{46}$

El beneficio de libertad durante el proceso en delitos correccionales fue otro de los puntos que Olmos consideró. Las exigencias de fianzas impuestas a los autores de robo y hurto fueron ampliadas en su proyecto también para los cómplices y encubridores de esos delitos, de estafa, defraudación, malversación de caudales públicos, fraudes y exacciones. Reforma que también trasluce la preocupación por la frecuencia con la que se calificaba a los autores principales como encubridores. ${ }^{47}$ Asimismo, propuso restringir la libertad procesal restableciendo la fianza real en casos de apelación de sentencias absolutorias o sobreseimientos, dado que el código procesal exigía como única condición que fijará domicilio dentro de la jurisdicción del juzgado.

Evitar la impunidad delictiva era la principal preocupación que guiaba las reformas de Olmos, con tal fin suprimía el artículo 381, que establecía que si no avanza la investigación el

\footnotetext{
${ }^{46}$ DSCS, (1919), Sesión 15-7-1919, p.182.

${ }^{47}$ DSCS (1919) Sesión 15-7-1919, p. 182.
} 
Sedeillán, G. El código procesal penal bonaerense de 1915: primeras iniciativas de reforma en la Legislatura a tres años de vigencia. Derecho y Ciencias Sociales. Abril 2018. N ${ }^{\circ}$ 18. Pgs 234-251. ISNN 1852-2971. Instituto de Cultura Jurídica y Maestría en Sociología Jurídica. FCJ y S. UNLP

sobreseimiento provisorio se convertía en definitivo a los tres años para aquellos casos de delitos con pena capital, de presidio o penitenciaria mayor a 10 años; a los dos años en casos de ser la pena menor a los 10; al año si se tratase de prisión y a los seis meses en caso de arresto o multa. Se preguntaba si no significa un exceso de liberalidad que el código redujera a términos incompatibles con la ley de fondo los plazos de la prescripción de la acción cuando el procesado se conformaba con el sobreseimiento provisional. ${ }^{48}$

Mientras los autores de los proyectos mencionados esperaban el despacho de la comisión de legislación, resulta interesante acercar la mirada a la opinión de Jofré, quien por entonces ocupaba una banca en Diputados por la oposición. Para este prestigioso jurista evitar la impunidad delictiva requería hacer del juez del crimen algo más que un instrumento de aplicación de la legislación. Consideraba que también debía otorgársele un papel importante en la prevención del delito. En tal sentido, el 23 de julio de 1919, reflotó un proyecto que ya había presentado años antes, cuya letra facultaba al juez, mediante juicio oral y público, a aplicar multas o penas no superiores a tres meses de arresto a individuos de "conducta desarreglada". Incluía bajo esta definición a quienes tenían casas de prostitución, a reincidentes sin medios de vida conocidos, a condenados por delitos contra la propiedad que no tuvieran forma de subsistencia, a los que vivían del juego, etc. ${ }^{49}$ En definitiva, daba potestad al juez para supervisar y castigar situaciones que la penología clásica no solía calificar como "delitos". 50

Con el propósito de maximizar la eficacia y eficiencia de la administración judicial, Jofré en 1920, presentó un proyecto para "reprimir el cuatrerismo" en particular, cuya letra incorporaba algunas disposiciones por él propuestas anteriormente. En esta oportunidad, sostuvo la necesidad de que la represión de los delitos contra la propiedad se complementase con la acción penal del propietario de ganado. ${ }^{51}$ Argumentó en tal sentido, que no era posible "que el estado asegure exclusivamente a los hacendados sus derechos de propiedad si ellos no toman las iniciativas que les corresponde." ${ }^{, 52}$ Al tiempo que destacó la necesidad de que organizaciones no gubernamentales actúen como querellantes en casos que afecten sus intereses, introdujo algunas reformas en el procedimiento penal.

\footnotetext{
${ }^{48}$ DSCS (1919) Sesión 15-7-1919, p. 187.

${ }^{49}$ DSCD, (1920) TII, sesión 23-7-1919.

${ }^{50}$ No se discutió en la legislatura la posibilidad de aplicar la noción de "estado peligroso" en la fase pre-delictiva con fines preventivos. Sobre este concepto y los proyectos presentados a nivel nacional: Marteau (2003); Salvatore $(2001 ; 2010)$.

${ }^{51}$ DSCD, (1921) sesión 20-8-1920, p. 872

${ }^{52}$ DSCD (1921) sesión 20-8-1920, p. 872.
} 
Sedeillán, G. El código procesal penal bonaerense de 1915: primeras iniciativas de reforma en la Legislatura a tres años de vigencia. Derecho y Ciencias Sociales. Abril 2018. N 18. Pgs 234-251. ISNN 1852-2971. Instituto de Cultura Jurídica y Maestría en Sociología Jurídica. FCJ y S. UNLP

El proyecto de Jofré, al igual que el resto de los presentados por entonces, buscaba otorgar al juez herramientas para fortalecer la persecución penal. Sin embargo, a diferencia de aquel presentado por Olmos, las reformas del código se limitaban a ampliar los plazos de la incomunicación. Más bien se detenía en eliminar formulismos que impedían comprobar el cuerpo del delito o su autor. Por ejemplo, fijaba que el simple juramento del propietario, mayordomo o encargado era suficiente para constar la preexistencia de los objetos substraídos. En particular, su propuesta continuó centrada en establecer la obligatoriedad del juicio oral con objeto de que el código ganara funcionalidad y eficacia. Procedimiento que siempre había pregonado por considerarlo más transparente y dinámico para esclarecer los hechos, agilizar los trámites y también resguardar las garantías del acusado. Argumentaba que: "En el juicio oral testigos y peritos están contenidos por el contralor que sobre ellos ejercen sus vecinos y amigos que asisten al proceso (...) es un espejo que refleja los hechos con notable precisión” (Jofré, 1919: 48). Difería de Olmos, quien por el contrario lo consideraba un obstáculo para la represión del delito.

Junto a los proyectos señalados también se propusieron reformas en el registro de marcas de propiedad de ganado a fin otorgar a los propietarios mayores instrumentos de seguridad. Existía amplio consenso en la deficiencia de la legislación que regulaba la expedición de guías para el tránsito de animales en la campaña. Algunos legisladores apuntaron a dar intervención a las comisarias para la transferencia de los certificados y Crotto, dictó decretos en tal sentido. Por su parte, Jofré fijó, en su proyecto contra el cuatrerismo de 1920, que toda persona que se dedicase al transporte o acarreo de hacienda debía estar muñida de una cédula de identidad otorgada por la policía donde conste que no ha sido condenado por delitos contra la propiedad, estableciendo multas en caso contrario. ${ }^{53}$

Los proyectos presentados no se convirtieron en ley, por lo que en términos de normativa procesal no se ampliaron las facultades punitivas del Estado. El proyecto del radical Olmos, ilustrativo de esa tensión entre el resguardo de las garantías y la eficacia del proceso penal ${ }^{54}$ no fue tratado. ${ }^{55} \mathrm{El}$ de Gambier, vencido el término reglamentario pasó a archivo, aunque su autor volvería a reflotarlo ante la dificultad de aprehender a los presuntos

\footnotetext{
53 También el juez del crimen Villar (1921: 34) destacaba las deficiencias en la materia, tal como los diarios analizados.

${ }^{54}$ Binder (1993) ha señalado que cada modelo de procedimiento criminal es una determinada síntesis de estas dos fuerzas. La dialéctica eficiencia/garantía.

55 Para 1920 Olmos ocupó una banca en la diputación nacional: Ferrari (2008)
} 
Sedeillán, G. El código procesal penal bonaerense de 1915: primeras iniciativas de reforma en la Legislatura a tres años de vigencia. Derecho y Ciencias Sociales. Abril 2018. N 18. Pgs 234-251. ISNN 1852-2971. Instituto de Cultura Jurídica y Maestría en Sociología Jurídica. FCJ y S. UNLP

culpables en estos delitos, ${ }^{56}$ no llegó a convertirse en ley durante el periodo abordado. En la legislatura pareció no existir voluntad política para debatir la reforma procesal, además de la falta de consenso contribuyó un escenario en el que las tensiones políticas repercutieron en la actividad legislativa. Pujas que impactaron negativamente en otras medidas que también hacían a la eficacia en la persecución penal, como por ejemplo lo era la lenta provisión de vacantes en la justicia.

\section{Conclusión}

Al asumir la Unión Cívica Radical la gobernación de la provincia de Buenos Aires, distintas voces señalaron en el ámbito político que el problema penal se centraba en la impunidad delictiva, en particular en relación al cuatrerismo. Los diagnósticos críticos se posaron no sólo en el insuficiente y poco capacitado personal policial o en las deficiencias del registro de la propiedad de ganado, sino también en el nuevo código procesal penal sancionado en 1915. Crotto, a pocos meses de estar al frente de la gobernación, destacó que la política criminal debía promover junto al aumento policial reformas en la legislación procesal a fin de conseguir mejores resultados en la lucha contra el crimen. Si bien más de una vez no estuvieron ausentes los reproches, las negaciones y las divergencias entre los políticos, la necesidad de introducir ajustes al código procesal fue compartida por algunos referentes de distintas afiliaciones políticas.

En la legislatura no existió voluntad política para discutir los primeros proyectos de reforma del código procesal que fueron presentados a fin de perfeccionar los mecanismos para atacar la criminalidad. Sin embargo, consideramos de interés destacar la línea general que los direccionaba. Lejos estaba de centrarse en cuan arbitrario y poco transparente era el procedimiento penal con el acusado y la necesidad de regularlo para que la persona sea sujeto y no objeto del proceso, como había acontecido en los años que precedieron a la sanción del código procesal de 1915. Aun cuando un conjunto de singularidades complejiza cualquier aproximación unilateral que tienda a leer esos proyectos como ilustrativos de cambios en la política criminal, traslucen cierto desplazamiento del eje de preocupación que dio impulso por esos años a los intentos de cambios en el proceso penal. En suma, la escasa eficiencia del corpus en la persecución penal adquirió peso a la hora de pensar su reforma.

\footnotetext{
${ }^{56}$ Moreno (1933) apoyándose en información brindada por la policía de la provincia, señalaba que en 1920 continuaba siendo baja la proporción de los aprehendidos por delitos contra la propiedad.
} 
Sedeillán, G. El código procesal penal bonaerense de 1915: primeras iniciativas de reforma en la Legislatura a tres años de vigencia. Derecho y Ciencias Sociales. Abril 2018. № 18. Pgs 234-251. ISNN 1852-2971. Instituto de Cultura Jurídica y Maestría en Sociología Jurídica. FCJ y S. UNLP

\section{Fuentes}

Diario de Sesiones de la Cámara de Diputados. (1921) La Plata: Taller de Impresiones Oficiales.

Diario de Sesiones de la Cámara de Diputados. (1920) La Plata: Taller de Impresiones Oficiales.

Diario de Sesiones de la Cámara de Diputados. (1919) La Plata: Taller de Impresiones Oficiales.

Diario de Sesiones de la Cámara de Senadores. (1919) La Plata: Taller de Impresiones Oficiales.

Diario de Sesiones de la Cámara de Senadores. (1918) La Plata: Taller de Impresiones Oficiales.

Diario de Sesiones de la Cámara de Diputados. (1917) La Plata: Taller de Impresiones Oficiales.

Nuevo código de procedimientos penales de la provincia de Buenos Aires, (1915). Prólogo de Tomas Jofré, Buenos Aires: Valerio Abeledo.

\section{Bibliografía}

Ascolani, A. (2013). "Trabajadores y sindicalismo". En Palacio J. M. (Dir.), Historia de la provincia de Buenos Aires. De la federalización de Buenos Aires al advenimiento del Peronismo (1880-1943), (Vol. 4). Buenos Aires: Edhasa/Unipe, pp. 393-418

Barba, F. (2010). José Camilo Crotto. Un gobierno en medio de la borrasca. Los primeros gobernadores radicales bonaerenses del siglo XX, de Cantilo a Monteverde. La Plata: Instituto Cultural de la Provincia.

Barba, F. (2009). “Un aspecto de la oposición radical yrigoyenista al gobernador Crotto, las interpelaciones Parlamentarias", Anuario del Instituto de Historia Argentina, (9), pp. 85-96.

Barba, F. (2007). "El proceso electoral de 1917 en la provincia de Buenos Aires y el triunfo de la U.C.R”, Anuario del Instituto de Historia Argentina, (7), pp. 11-29.

Barreneche O. (2010). "De brava a dura. La policía de la provincia de Buenos Aires durante la primera mitad del siglo XX”, Cuadernos de Antropología Social, (32), pp. 3156.

Barreneche, O; Galeano, D (2008). "Nota sobre las reformas policiales en la Argentina, siglos XIX y XX”. En: Masquelet, H. (Dir.). (2008). Cuadernos de Seguridad, (8), La Plata: Consejo de Seguridad Interior del Ministerio de Justicia. pp. 73-112.

Binder A. (2016). "La reforma de la justicia penal en América Latina como política de largo plazo". En Niño C. (Coord.). La Reforma a la Justicia en América Latina: Lecciones aprendidas. Colombia: Friedrich-Ebert-Stiftung. Recuperado el 20 septiembre de 2017 de https//www.library.fes.de/pdf-files/bueros/la-seguridad/12574.pdf.

Binder, A. (1993) Introducción al Derecho Procesal Penal. Buenos Aires: Ad-Hoc.

Caimari, L. (2009). La ciudad y el crimen. Delito y vida cotidiana en Buenos Aires, 18801940. Buenos Aires: Sudamericana. 
Sedeillán, G. El código procesal penal bonaerense de 1915: primeras iniciativas de reforma en la Legislatura a tres años de vigencia. Derecho y Ciencias Sociales. Abril 2018. № 18. Pgs 234-251. ISNN 1852-2971. Instituto de Cultura Jurídica y Maestría en Sociología Jurídica. FCJ y S. UNLP

Caimari, L. (2004). Apenas un delincuente. Crimen, castigo y cultura en la Argentina, 18801955. Buenos Aires: Siglo Veintiuno editores.

Cesano, J. (2011). Élites, redes intelectuales y recepción en la cultura jurídico penal de Córdoba: 1900-1950. Córdoba: Ediciones del Copista.

Cantilo, J. (1918). Intervención nacional en la provincia de Buenos Aires: 1917-1918; informe elevado por el interventor nacional, Don José Luis Cantilo al poder ejecutivo de la Nación. La Plata: Publicación Oficial.

Degregori, D. (1996). "El gasto público en la provincia de Buenos Aires, 1914-1940". Faces, 2(2), pp. 27-47.

Devoto, F. y Ferrari, M. (1994). La construcción de las democracias rioplatenses: proyectos institucionales y prácticas políticas, 1900-1930. Buenos Aires: Biblos.

Fernández Irusta, P. (2006). "El Partido Conservador de la Provincia de Buenos Aires y el proceso de democratización bonaerense”, Estudios Sociales, 31 (1), pp. 95-135.

Ferrari, M. (2008). Los políticos en la república radical. Prácticas políticas y construcción de poder. Buenos Aires: Siglo XXI editores.

Ferrari, M. (1994). "Persistencias y transformaciones en las redes de fidelidad política a través de los resultados electorales en la Provincia de Buenos Aires. 1914-1921”. En Devoto, F. y Ferrari, M. (Comp.). La construcción de las democracias rioplatenses: proyectos institucionales y prácticas políticas, 1900-1930. Buenos Aires: Biblos, pp. 137-167.

Gerchunof, P. (2016). El eslabón perdido. La economía política de los gobiernos radicales (1916-1930), Buenos Aires: Edhasa.

Guariglia, F. y Bertoni, E. (2000). "Bases político-jurídicas del procedimiento penal”. En Maier, B.; Kai Ambos; Woischnik J. (Coord.) Las reformas procesales penales en América Latina. Buenos Aires: Ad·Hoc. pp. 35-74

Jofré, T. (1919). Manual de procedimientos civil y penal, 2 ed. (Vol. 1). Buenos Aires: Valerio Abeledo.

Jofré, T. (1915). El nuevo código de procedimiento penal. (Vol. 1). Buenos Aires: Lajouane.

Jofré, T. (1914). Proyecto de código de procedimientos penal. Buenos Aires: Suarez.

Maier, J. (1989). Derecho procesal Penal Argentino. (Vol. 1.b). Buenos Aires: Hammurabi.

Marteau, F. (2003). Las palabras del orden. Proyecto republicano y cuestión criminal en Argentina. Buenos Aires 1880-1930. Buenos Aires: Ediciones del Puerto.

Melon, J. y Pastoriza, E. (1996) Los caminos de la democracia. Alternativa y prácticas políticas, 1900-1943. Buenos Aires: Biblos.

Moreno, R. (1933) El problema penal, Buenos Aires: Rosso.

Moreno, R. (1922) El código penal y sus antecedentes, (Vol. 1). Buenos Aires: Tommasi.

Palomeque, A. (1916) Comentarios y críticas al nuevo código de procedimientos penal de la provincia de Buenos Aires, Buenos Aires: Sopena.

Persello, V. (2013) "El radicalismo Bonaerense". En Palacio J. M. (Dir.), Historia de la provincia de Buenos Aires. De la federalización de Buenos Aires al advenimiento del Peronismo (1880-1943), (Vol. 4). Buenos Aires: Edhasa/Unipe, pp. 285-308.

Persello, V. (2007). Historia del radicalismo. Buenos Aires: Edhasa. 
Sedeillán, G. El código procesal penal bonaerense de 1915: primeras iniciativas de reforma en la Legislatura a tres años de vigencia. Derecho y Ciencias Sociales. Abril 2018. N 18. Pgs 234-251. ISNN 1852-2971. Instituto de Cultura Jurídica y Maestría en Sociología Jurídica. FCJ y S. UNLP

Persello, V. (2000). "Los gobiernos radicales: debate institucional y práctica política". En Ricardo Falcón (Dir.) Democracia, conflicto social y renovación de ideas (1916-1930). Buenos Aires: Sudamericana.

Persello V. (1996). “El partido Radical. Oposición y gobierno.” Estudios Sociales, 11, pp.6784.

Regalsky, A. y Da Orden, V. (2013). “Banca y finanzas públicas”. En Palacio J. M. (Dir.), Historia de la provincia de Buenos Aires. De la federalización de Buenos Aires al advenimiento del Peronismo (1880-1943), (Vol. 4). Buenos Aires: Edhasa/Unipe, pp. 251284.

Ruffini, M. (1993). "Un aspecto de la relación Yrigoyen- Crotto. Agro y política en la provincia de Buenos Aires". Estudios de historia rural III, 15, pp. 35-37.

Salvatore, R. (2010). Subalternos, derechos y justicia penal. Ensayos de historia social y cultural Argentina 1829-1940. México: Gedisa.

Salvatore, R. (2001). "Sobre el surgimiento del estado médico legal en la Argentina (18901940)”. Estudios Sociales, 20. pp. 81-114.

Sedeillan, G. (2013) "Procedimiento judicial y prisión preventiva: proyectos de reforma en la provincia de Buenos Aires ante la sobrepoblación carcelaria (1903-1915). En Salvatore R., y Barreneche O., (Comp.). El delito y el orden en perspectiva histórica, Rosario: Prohistoria.

Tato, M. (2005). "Variaciones reformistas: los conservadores bonaerenses ante el desafío de la democratización, 1912-1919.” Secuencia, 63, pp. 129-150.

Walker, R. (1987). La provincia de Buenos Aires en la política argentina. Buenos Aires: Emecé.

Vélez Mariconde, A. (1969). Derecho procesal penal. Buenos Aires: Lerner.

Villar Sáenz Peña, L. (1921). El cuatrerismo. Buenos Aires: Lajouane.

Zimmermann, E. (1995). Los liberales reformistas. La cuestión social en la Argentina 18901916. Buenos Aires: Sudamericana. 